\title{
The Evolution of Social Beliefs 1960-2016 in the United States and Its Influence on Empathy and Prosocial Expression in Medicine
}

This article was published in the following Dove Press journal:

Advances in Medical Education and Practice

\section{Reginald F Baugh (D)}

University of Toledo College of Medicine and Life Sciences, Toledo, $\mathrm{OH}$ 43623, USA
Correspondence: Reginald F Baugh University of Toledo College of Medicine and Life Sciences, 3000 Arlington Avenue, MS 1905, Toledo, OH 43623, USA

$\mathrm{Tel}+$ I 4|9-383-6834

Email reginald.baugh@utoledo.edu

\begin{abstract}
This perspective surveys healthcare's response to the increased prominence of racial, ethnic, religious and sexual minorities as well as females in American culture. It argues for understanding physicians both as products of the broader society and its changes. Starting in the 1960s, empiric evidence for the rise of reactionary viewpoints in response to major social movements is outlined. Structural reasons for the prevalence of such ideologies within medicine are highlighted. Its negative consequences for minority health are addressed. Finally, the author turns to compensatory strategies to improve the social environment within healthcare. Alternative selection strategies for medical school are proposed, with a stronger focus on empathetic candidates.
\end{abstract}

Keywords: social beliefs, empathy, diversity and inclusion, social justice, medical school admissions, discrimination, multiculturalism, assimilation

\section{Plain Language Summary}

This perspective essay provides insights into how biographical experience, motivation, and personality traits have changed in response to the social turmoil of the 1960s and 1970s. Who we are today is in part a result of our collective responses to that turmoil and may have potentiated a decline in prosocial traits in medical students. The challenges of preparing students are better understood when viewed within the broader social context. We are different and so are our students. The current medical school curriculum and pedagogy deserve scrutiny regarding the effectiveness by which they are acculturating students to medicine's humanistic ideals as the broader society has become more polarized. The rise of social media is used to illustrate how medicine may not have kept pace with the changes in social beliefs. To the extent we fail, our patients and profession suffer. The population of potentially successful medical school students expressing greater prosocial tendencies far exceeds the chosen few. Different selection methodologies will be required while we successfully develop effective strategies.

\section{Introduction}

As public discourse has increasingly turned to the American healthcare system, one of many concerns is its ability to offer high-quality care to a diverse society. Sociology and group psychology offer important insights into this dialogue. The medical training environment can be treated as its own subculture with two controlling facts. First, while the code of medical ethics has remained relatively stable over more than a century, actual physician beliefs and attitudes in the US have 
tended to reflect broader social norms. Second, the residency model of training lends residents and attending physicians tremendous influence to transmit not only their medical skills but their ideas and customs as well. A proper understanding of the social attitudes imparted by medical education requires accounting for the impact of social currents during the formative years of physicians' lives. We briefly trace the trajectory of American culture on issues of diversity and pro-social behavior, examine more contemporary manifestations and examine its impact on the current climate of hospital training programs.

As the social and cultural turmoil of the 1960s and 1970s manifested in American youth, researchers began documenting changes within them. Narcissism, individualism, and materialism became more prevalent. After the mid-1970s, people increasingly adopted a belief in a just world (BJW) as their philosophy: that "people get what they deserve and deserve what they get". ${ }^{1}$ As a central tenet of the meritocracy argument, BJW provided a ready justification for inequality and status quo preservation during tumultuous times. Collectivism, empathy, and the trust of others started deteriorating, and people who opposed changes to the social order and culture of the 1950s legitimized the existing social system. ${ }^{2}$ As societal forces contradicted their beliefs, BJW individuals felt threatened and stressed. Perhaps predictably, their embrace of BJW was associated with a tendency to denigrate, blame, and stigmatize "others" 3,4 as they adhered more strongly to their underlying beliefs ${ }^{1}$ and manifest prejudice. 5 Differences in the perception of how "others" (women, LGBT+, immigrants, religious minorities, Asians, Hispanics, African-American/Blacks, Native Americans, Native Alaskans, Native Hawaiians, and other Pacific Islanders) live, believe, detect, and process cues that they perceive as a rejection of their dominance may have heightened people's susceptibility to social stressors. ${ }^{4}$ Around the year 2000, the strengthening of all these factors among the American public led some to perceive multicultural pluralism as a threat. ${ }^{6}$

As Americans, we also underwent profound change. The long-term trend of 1970s, narcissism and materialism increased during the Great Recession although collectivism rose and individualism decreased, ${ }^{7}$ albeit momentarily, in response to the common economic threat. ${ }^{8}$ In the following years, individualism, ${ }^{9,10}$ materialism, and narcissism left a lasting impact. ${ }^{11}$ The perception that anti-white discrimination exceeds racial/ethnic discrimination progressively increased as "others" began to enjoy greater liberties during the Civil Rights era. The hostile social climate of the period was permissive, as individuals express prejudiced attitudes and behavior more freely. ${ }^{12,13}$ Homophily rose as political divisions sharpened along with widening of rifts along racial/ethnicity, age, religion, education, and gender. ${ }^{14}$ This same period also saw a rise in hate crimes against racial/ ethnic minorities, the LGBT community, the homeless, and immigrants. ${ }^{15}$ Immigration from non-European countries (both legal and illegal) increased during the 1980s, raising their visibility. Anti-Semitism sharply intensified as groups previously within the mainstream found themselves considered outsiders. $^{16}$

Experimental evidence suggests that narcissism's rise over the last 40 years would be accompanied by heightened social dominance orientation and indirectly associated with increased prejudice. ${ }^{17}$ As expected, narcissists hold more significant prejudicial attitudes toward "others," to the extent that such attitudes satisfy their feelings of entitlement and encourage their desire to dominate and exploit others. Correspondingly, narcissism has been associated with antisocial tendencies, such as interpersonal aggressiveness, ${ }^{18}$ negative perceptions of humanity, ${ }^{19}$ and unsatisfactory academic performance. ${ }^{20}$ Mistrust of others continued its 40year increase into the first decade of the 21 st century. ${ }^{11,21,22}$ Importantly, the same period saw a $40 \%$ decline in empathy among college students ${ }^{7,23}$ just as social anxiety regarding multicultural pluralism as a social motivator was becoming evident. Researchers also documented a decline in dispositional empathy, especially after $2000 .^{7}$ Changes were greatest in empathetic concern and perspective-taking, ${ }^{10}$ traits which mitigate callousness ${ }^{24}$ and prejudice. ${ }^{25}$ Lower empathy levels were linked to prejudice against a range of stigmatized targets; ${ }^{26}$ conversely, higher levels were associated with lower prejudicial attitudes toward different stigmatized groups. $^{27}$

Toward the end of the 20th century, blatant discrimination was less acceptable. ${ }^{28}$ Rather than a marked increase in egalitarian or non-prejudiced views, however, the expressions of prejudice changed (eg, rejecting members of marginalized groups for non-prejudiced reasons). ${ }^{18,19,29,30}$ Other more obvious biological falsehoods rooted in slavery continued to influence the treatment of "others" 31 in medicine. The tendency to underestimate the level of income inequality $^{32,33}$ and overestimate intergenerational social mobility ${ }^{34,35}$ served to provide justification for conscious and unconscious biased attitudes and behaviors. Ambivalent anti-“other" feelings and stereotypes gave rise to selective incivility (microaggressions). ${ }^{36}$ Such behavior 
toward marginalized and stigmatized groups appears pervasive in our schools and residences. ${ }^{37,38}$

\section{Consequences of Cultural Turmoil When Fear Became the Lens}

After 2000, fear became the lens as dramatic demographic changes (immigration), struggles for equality and social justice by diverse groups (Black Lives Matter, \#MeToo movement, Women's March), and the greater visibility of "others" triggered increased social anxiety ${ }^{39}$ and nostalgia for an idealized mythical time in America's past. Social organizations ${ }^{40}$ and civic engagement, ${ }^{41}$ which could have helped mitigate such anxiety, either disappeared or saw a dramatic decline in participation. ${ }^{42}$

The public's response has been to "hunker down" and to perceive "others" as threatening and untrustworthy, and both its economic and social fears have been seemingly catalyzed by the lack of real wage growth in the last 40 years. The increasing prominence of "others" fostered the impression that it has emerged at the dominant group's expense because they believe that the situation was a zerosum game, a view not shared by minority groups. ${ }^{43-45}$ The resulting shift in perceptions provoked an increased opposition to diversity, ${ }^{45,46}$ a higher propensity for implicit and explicit bias, and homophilia. ${ }^{47}$ For some, the rise of "others" evoked fears of rejection and suppression of white cultural values and norms, as evident in the perceived "war on Christmas" or the resentment of "political correctness". 46

During the period 2012-2016, social dominance orientation - a marker for prejudice and discrimination -increased significantly. ${ }^{48}$ A robust body of literature provides empirical evidence of the widespread correlates of social dominance orientation and its theorized critical role in helping determine the nature of human sociality. ${ }^{49}$ Individuals with high social dominance orientation tend to view individuals not as separate entities but as representatives of social categories. Such individuals experience empathetic concern less frequently and to a reduced degree. ${ }^{50}$ Further, when confronted with contrary information, they resist changing their stereotype-based judgments. ${ }^{51}$ This may account for the increase manifestation of social dominance orientation with clinical exposure ${ }^{52}$ with its greater diversity and curricular exposure to social determinants of health (SDH) information.

\section{Prejudice, Discrimination, Implicit Bias}

Prejudiced behavior is meant to serve a specific function dictated by the context of its expression, ${ }^{53}$ the degree, ${ }^{54}$ and means of expression, as well as which components are communicated. ${ }^{55}$ The intention or awareness of prejudicial response may be unconscious, although the concept of unconscious discrimination is being increasingly challenged as a fiction. ${ }^{56-58}$ At any time, we take different identities and group memberships. Through deontological theory, under professionalism, we provide specific moral/ ethical rules suggesting that an action's morality is determined by whether it conforms to a set of professional rules (eg, no patients should face discrimination). ${ }^{59}$ We try to make the "ideal physician" ingroup the most salient in professional matters, if not overall. Often, we fail because of the persistence of innate discrimination ${ }^{60,61}$ and the lack of moral development ${ }^{62}$ (ie, they never learned not to discriminate).

Favorable behavior in accordance with medical school professionalism and SDH instruction, ${ }^{59}$ while mostly congruent with practicing physicians' ideals, generates significant dissonance with medical students because of the inconsistency between pervasive faculty misbehavior, ${ }^{63}$ professed ideals, and conflicts with personal beliefs. Rather than the wholesale adoption of professionalism, a more nuanced interpretation arises where professional behavior is associated with the self-perception of being a "good person" 64 allowing potential biases to intrude. ${ }^{65}$ Moreover, for more than one-third (36\%) of medical students (those in the "strong racial bias" category ${ }^{66}$ - a rate $30 \%$ higher than a comparable segment of the US population ${ }^{67}$ ), they may exhibit significant internal dissonance to professionalism standards as well. Assumptions regarding positive beliefs or attitudes about marginalized or stigmatized populations may be far from inevitable or responsive to educational efforts.

Unsurprisingly, physician surveys demonstrate that regardless of specialty, an implicit preference for whites is present. ${ }^{61,68}$ This finding is important because empathy, the core of quality medicine, actively mediates implicit bias against others, reducing prejudice and discrimination. ${ }^{25}$ Polling indicates that one in five Americans explicitly do not believe all men are created equal, a bedrock moral precept in medicine. ${ }^{69}$ Medical students and physicians are aware of stereotypes about racial/ethnic minorities. ${ }^{70-72}$ Levels of implicit bias against African Americans, Hispanics, and other people of $\operatorname{color}^{72,73}$ by physicians are 
similar across groups and comparable to the general population. ${ }^{73,74}$

Physician biases, both explicit and implicit, matter. The ideological orientations that people have toward diversity have real consequences and exert real influence on inclusion $^{75}$ and health equality. Despite the lack of clearcut offs, higher implicit bias is important as providers with a stronger implicit bias towards "others" have demonstrated poorer patient-provider communication ${ }^{76}$ and are more likely to deliver inferior care. ${ }^{77,78}$ Implicit bias against "others" significantly impacts patient-provider interactions, treatment decisions, treatment adherence, and patient health outcomes. ${ }^{73}$ Bias associations are strongest for patient-provider interactions and related health outcomes. ${ }^{73}$ Even the small influences of implicit bias in the educational environment can cascade and have significant effects on medical school grades, selections for awards for "others" and ultimately adversely affecting their medical career. ${ }^{79}$ Deliberative decisions typical of healthcare decisions are probably not as unconscious as commonly believed. ${ }^{57,58}$ Professed good intentions and conscious egalitarian views are not enough to reduce the adverse impact of implicit bias on clinical care ${ }^{80}$ remain associated with bias medical decision-making, ${ }^{81}$ and presumably are not enough to mitigate decreases in empathy and the related value of humanism. ${ }^{82}$

\section{Social Media}

Medical student involvement with social media is now ubiquitous. Social forces acting through social media has heavily changed the way we get informed and how we shape our opinions. Few appreciate how these platforms foster "somewhat inevitable" 83 or "eventually" form a homogeneous cluster, resulting in assimilation or even amplification of beliefs ${ }^{84}$ and homophilic tribal tendencies. In these homogeneous groups, similar beliefs develop that lead to a degradation of the quality and diversity of topics and discussion online. Even within the echo chamber, the formation of highly polarized sub-clusters within the same echo chamber occurs. ${ }^{85}$ Fundamentally, individuals want validation of their identity and experiences. ${ }^{86}$ Social media alleviates the uncertainty of social interactions motivating individuals to establish shared realities through group identification. Confirmation bias facilitates informational cascades and the aggregation of favored information that reinforces selective exposure and group polarization. ${ }^{85} \mathrm{It}$ provides a self-saturating reality that is shared absolutely.
Social forces reinforced in "echo chambers" lead to increased strong negative emotions members of one group feel toward another ${ }^{87}$ through repetitive approval by their social group and the enhancement of extant tendencies, beliefs, and biases to better align with group norms. Within these bubbles, the communication often surrenders rationality in favor of conformity to the group. ${ }^{88}$

Online expression leads to belief enhancement, makes it less vulnerable to change, activates attitude change and action commitments. ${ }^{89}$ Positive endorsements from social media can reduce the persuasive power of counterattitudinal information from other sources. ${ }^{90}$ Greater time in the social media bubble and lower ambiguity tolerance (a characteristic associated greater use of stereotypes, ${ }^{91}$ a decline in attitudes toward underserved populations), ${ }^{92}$ leads to a significantly higher overestimation of public support for the opinions expressed ${ }^{93}$ and greater resistance to change from those views expressed within the bubble. Summarily, those medical students with expressed greater social media exposure likely will experience less receptiveness to educational efforts that present contrary information to their existing beliefs (eg, SDH messaging or interactions with diverse peoples). This is vitality important since poorly designed, targeted, or executed interventions are not just ineffective but reinforce people preexisting beliefs. ${ }^{94,95}$ Current curriculum efforts are often undertaken without consideration of the role social beliefs or how social media may have changed the receptiveness of students. Although it is often undertaken to identify users' behavior on social media for determining targets and tailoring corrections in the form of fact-checking or debunking attempts, ${ }^{96}$ attempts to identify the best interventions based upon their social media use and prevalent social beliefs remains speculative.

The "real teacher," who socializes students on what is "actually" valued in medical education and medical practice, the hidden curriculum is replacing the formal curriculum as a foundation of medical training. ${ }^{97,98}$ Further, the hidden curriculum fosters the devaluation of the professional group identity and salience, promoting the substitution of personal values in the best of circumstances and the adoption of hidden curriculum values in the worst. Even among those wishing to resist the hidden curriculum, faculty misbehavior and exhibition of conflicting values may undermine their desires. ${ }^{99}$ Thus, the more faculty role model discriminatory behavior and values contrary to 
established medical values, the greater student implicit bias is found among students. ${ }^{100}$

Hence, to produce students more reflective of established medical values, the curricula must acknowledge the now ubiquitous presence and role of social media and that the hidden curriculum must change. The failure of nearly every effort to eradicate the hidden curriculum has failed because of a misconception of the problem. The problem is not some hidden minority of "bad actors", it is the silent majority that give their tacit approval. The hidden curriculum reflects prevalent social beliefs within the faculty. Therefore, without attitudinal change among faculty or until there's greater willingness to use different selection factors for students and faculty, the hidden curriculum is not going to change.

The identification and selection of applicants already manifesting the desired characteristics seem preferable to selecting applicants not already manifesting those characteristics and trying to change them. Designing the selection process to favor both faculty and students with a sustained history of prosocial activities; ${ }^{101-103}$ rejection of academic linearity, the adoption of academic threshold selection will increase the diversity of candidates, and the pool of prosocial students will significantly alter the composition of medical schools ${ }^{104}$ toward greater student empathy. ${ }^{105,106}$

Discrimination in healthcare has significant adverse consequences for those subject to bias. Prejudice in healthcare potentially negatively and disproportionately impacts more than two-thirds of the deaths in America ${ }^{107}$ and extends beyond the doctor-patient relationship to include healthcare administration, ${ }^{108}$ academic and research leadership, and the research agenda. ${ }^{109}$ Such differences longitudinally are not insignificant and may account for up to 6 years shorter life expectancy among some "others". ${ }^{110}$ Even some upwardly mobile "others" are significantly more likely to experience both acute and chronic discrimination in healthcare than their white counterparts. ${ }^{111}$ Differential exposure to unfair treatment explains a substantial portion of the differences in selfrated health in "others". ${ }^{111}$ Colorism may account for the more limited findings among Hispanics. ${ }^{72,112}$

\section{Guiding Principles}

The fundamental principle that should guide our actions is that all students, irrespective of gender, race, religion, ethnicity, country of origin, sexual orientation have the right to enjoy the full benefits of medical school enrollment. ${ }^{113-117}$ Currently, they do not. The discriminatory challenges within medical schools faced by "others" whether conscious or unconscious, makes their educational experience and opportunities unequal. ${ }^{118}$ Equality is inseparable from, and dependent on, diversity within our classes. ${ }^{113-116}$ Hence, the limited student and faculty diversity of our medical schools is a threat to the diversity of thought and perspectives necessary for the optimal learning environment in medical school, ${ }^{119,120}$ for quality patient care, and achieving health equity.

Current medical school environments implicitly value biomedical learning more than empathic behavior. ${ }^{121-124}$ Negative role models, ${ }^{29}$ a chronic shortage of time (ie, lack of reflective time), ${ }^{122,123,125,126}$ and the competitive nature $^{127}$ of medical schools act in concert within the hidden curriculum to inhibit empathy development. In this environment, the only empathy exhibited by students is often manipulative, false, and does not facilitate moral values. $^{128}$

Unfortunately, most medical students have had limited experiential exposure to or understanding of "others" to buffer prevailing adverse influences due to rising socioeconomic class inequality ${ }^{128,129}$ and rising residential and economic segregation over the past few decades. ${ }^{45,130-133}$ For even in diverse neighborhoods, actual contact between whites and "others" remains low. ${ }^{134}$ Similar to findings from 2 decades ago, ${ }^{135,136}$ a recent national collegiate survey found no consistent development of positive attitudes towards "others" ${ }^{137}$ Increased homophily during their freshman year ${ }^{137}$ and the deliberate lack of significant interactions with "others" are postulated reasons. ${ }^{138}$ Favorable contact with stigmatized groups can change attitudes overcoming students' baseline levels of social dominance orientation, dispositional empathy, or need for cognitive closure. ${ }^{139}$ Both the amount and favorability of contact predicts positive implicit and explicit attitudes. ${ }^{140}$

\section{Change}

All change begins as personal change. The individual actions of physicians and the collective performance of medical schools result from the consensus of individual decisions and behavioral and sociocultural practices. Each medical school process is shaped by consensually held values, attitudes, beliefs, and cultural ideologies, ${ }^{49}$ which, unfortunately, reflect the prevalent beliefs and attitudes of the medical school population and general public. ${ }^{68,73,74}$ The force of beliefs that support and lead to the persistence of the hidden curriculum is similarly 
propelled by the consensus across constituent groups. $^{75,141}$ When more egalitarian views of health equity are more widely accepted among faculty and staff, the more effective those that support such beliefs will be in changing the status quo. Summarily, when the consensus of medical school faculty decides to change the hidden curriculum, it will go away. To the extent physician views continue to reflect those of the general public, such a change is not likely to occur. Each physician, can, however, determine the speed and direction of change by the values, attitudes, and beliefs they elect to manifest rather than just espouse.

Previously successful strategies for the indoctrination of empathetic, humanistic principles and beliefs into students will require revision as those strategies may not have kept pace with the rate of social change. The current medical school curriculum and pedagogy have yet to educate students adequately about stigmatized and marginalized people ${ }^{142,143}$ and have not adequately educated students as the broader society has become more polarized and diverse. Novel strategies may be more successful than traditional ones in acculturating millennial students.

\section{Conclusions}

Today's medical environment is very different from that of 50 years ago. The cumulative changes that have resulted from the social forces at work in the last half-century in the United States are profound. Our patients differ from the ones in the past, and we have changed too. Millennials, who constitute the bulk of those in training, enter medical school with very different ideas about medicine, its practice, and their patients. The spectrum of values, attitudes, and beliefs this generation hold may be more divergent from medicine's humanistic roots than in previous generations.

"Our future is not in the stars but in our own minds and hearts". ${ }^{144}$ Fostering leadership, learning, and empathy between cultures was and remains a central purpose of medical education. In the next 20-30 years, America will be a majority-minority country. This generation of physicians is not prepared to care for the population they will be privileged to care for. While innovations may provide future direction, the problem is present right now, and the situation is likely to get worse in the coming decades to the detriment of the health of the country and our people. The population of potentially successful medical school students far exceeds the chosen few. Different selection methodologies will be required while we successfully develop successful strategies.

\section{Disclosure}

The author reports no conflicts of interest in this work.

\section{References}

1. Malahy LW, Rubinlicht MA, Kaiser CR. Justifying inequality: A cross-temporal investigation of U.S. income disparities and just-world beliefs from 1973 to 2006. Soc Just Res. 2009;22:369-383. doi:10.1007/s11211-009-0103-6

2. Brandt MJ, Reyna C. Individual differences in the resistance to social change and acceptance of inequality predict system legitimacy differently depending on the social structure. Eur J Pers. 2017;31(3). doi:10.1002/per.2100

3. Sutton RM, Douglas KM. Justice for all, or just for me? More evidence of the importance of the self-other distinction in just world beliefs. Pers Individ Dif. 2005;39:637-645. doi:10.1016/j. paid.2005.02.010one

4. Ariely D, Berns GS. Neuromarketing: the hope and hype of neuroimaging in business. Nat Rev Neurosci. 2010;11:284-292. doi:10.1038/nrn2795

5. Crawford JT, Mallinas SR, Furman BJ. Ideological attitudes on inter-group antipathy across the political spectrum. Pers Soc Psychol Bull. 2015;41:1607-1622. doi:10.1177/0146167215603713

6. Konrath SH, O'Brien EH, Hsing C. Changes in dispositional empathy in American college students over time: meta-analysis. Pers Soc Psychol Rev. 2011;15(2):180-198. doi:10.1177/1088 868310377395

7. Park H, Twenge JM, Greenfield PM. The great recession: implications for adolescent values and behavior. Soc Psychol Pers Sci. 2014;5(3):310-318. doi:10.1177/194855061349541

8. Greenfield PM. Linking social change and developmental change: shifting pathways of human development. Dev Psychol. 2009;45:401-408. doi:10.1037/a0014726

9. Hamamura T. Are cultures becoming individualistic? A crosstemporal comparison of individualism-collectivism in the United States and Japan. Pers Soc Psychol Rev. 2012;16:3-24. doi: $10.1177 / 1088868311411587$

10. Twenge JM, Campbell WK, Gentile B. Increases in individualistic words and phrases in American books, 1960-2008. PLoS One. 2012;7:e40181. doi:10.1371/journal.pone.0040181

11. Twenge JM, Campbell WK, Carter NT. Declines in trust in others and confidence in institutions among American adults and late adolescents, 1972-2012. Psychol Sci. 2014;25(10):1914-1923. doi: $10.1177 / 0956797614545133$

12. Crandall CS, Eshleman A. A justification-suppression model of the expression and experience of prejudice. Psychol Bull. 2003;129:414-446. doi:10.1037/0033-2909.129.3.414

13. Crandall CS, Eshleman A, O'Brien L. Social norms and the expression and suppression of prejudice: the struggle for internalization. J Pers Soc Psychol. 2002;82:359-378. doi:10.10 37/0022-3514.82.3.359

14. McPherson M, Smith-Lovin L, Cook JM. Birds of a feather: homophily in social networks. Ann Rev Soc. 2001;27:415-444. doi:10.1146/annurev.soc.27.1.415

15. Civil Rights Education Fund. Confronting the New Faces of Hate: Hate Crimes in America 2009. Washington, DC: Leadership Conference on Civil Rights Education Fund;2009.

16. Anti-Defamation League. 2017 Audit of anti-semitic incidents. AntiDefamation League; February 2018. Available from: https://www.adl. org/news/press-releases/anti-semitic-incidents-surged-nearly-60-in -2017-according-to-new-adl-report. Accessed October 17, 2018. 
17. McConahay JB. Modern racism, ambivalence, and the modern racism scale. In: Dovidio JF, Gaertner SL, editors. Prejudice, Discrimination, and Racism. San Diego, CA: Academic Press; 1986:91-125.

18. Gaertner SL, Dovidio JF. Aversive racism. Adv Exp Soc Psychol. 2004;36:1-52.

19. Frey DL, Gaertner SL. Helping and the avoidance of inappropriate interracial behavior: a strategy that perpetuates a nonprejudiced self-image. J Pers Soc Psychol. 1986;50 (6):1083-1090. doi:10.1037/0022-3514.50.6.1083d

20. Ronningstam E. Identifying and Understanding the Narcissistic Personality. Oxford: Oxford University Press; 2005.

21. Konrath SH, Chopik WJ, Hsing CK, O'Brien E. Changes in adult attachment styles in american college students over time: a meta-analysis. Pers Soc Psychol Rev. 2014;18(4):326-348. doi: $10.1177 / 1088868314530516$

22. Twenge JM, Campbell WK. Birth cohort differences in the monitoring the future dataset and elsewhere: further evidence for generation me - commentary on Trzesniewski \& Donnellan (2010). Pers Psychol Sci. 2017;5(1):81-88. doi:10.1177/1745691609357015

23. Twenge JM, Campbell SM. Generational differences in psychological traits and their impact on the workplace. J Manag Psychol. 2008;23(8):862-877. doi:10.1108/02683940810904367

24. Beussinka CN, Hackneya AA, Vitaccob MJ. The effects of perspective taking on empathy-related responses for college students higher in callous traits. Pers Individ Dif. 2017;119:86-91. doi:10.1016/j.paid.2017.07.005

25. Pashak T, Conley M, Whitney D, Oswald S, Heckroth S, Schumacher E. Empathy diminishes prejudice: active perspective-taking, regardless of target and mortality salience, decreases implicit racial bias. Psychology. 2018;9:1340-1356. doi:10.4236/psych.2018.96082

26. Hodson G, Dhont K. The person based nature of prejudice: individual difference predictors of intergroup negativity. Eur Rev Soc Psychol. 2015;26(1):1-42. doi:10.1080/10463283.2015.1070018

27. Bäckström M, Björklund F. Structural modeling of generalized prejudice; the role of social dominance, authoritarianism, and empathy. J Individ Dif. 2007;28:10-17. doi:10.1027/1614-0001. 28.1.10

28. Burridge J. 'I am not homophobic but .... disclaiming in discourse resisting repeal of section 28. Sexualities. 2004;7 (3):327-344. doi:10.1177/1363460704044804

29. Pettigrew TF, Meertens RW. Subtle and blatant prejudice in Western Europe. Eur J Soc Psychol. 1995;25:57-75. doi:10.10 02/ejsp.2420250106

30. Meertens RW, Pettigrew TF. Is Subtle prejudice really prejudice? Public Opin Q. 1997;6154-6171. doi:10.1086/297786

31. Hoffman KM, Trawalter S, Axt JR, Oliver MN. Racial bias in pain assessment and treatment recommendations, and false beliefs about biological differences between blacks and whites. PNAS. 2016;113(16):4296-4301. doi:10.1073/pnas.1516047113

32. Hauser OP, Norton MI. (Mis)perception of Inequality. Cur Opin Psychol. 2017;18:21-25. doi:10.1016/j.copsyc.2017.07.024

33. Kraus MW, Rucker JM, Richeson JA. Americans misperceive economic equality. PNAS. 2017;114(39):10324-10331. doi:10.10 73/pnas.1707719114

34. Davidai S, Gilovich T. Building a more mobile America - one income quintile at a time. Perspect Psychol Sci. 2015;10:60-71. doi:10.1177/1745691614562005

35. Kraus MW, Tan JJX. Americans overestimate social class mobility. J Exp Soc Psychol. 2015;58:101-111. doi:10.1016/j. jesp.2015.01.005

36. Dovidio JF, Gaertner SL, Ufkes EG, Saguy T, Pearson AR. Included but invisible? Subtle bias, common identity, and the darker side of 'we.'. Soc Iss Pol Rev. 2016;10(1):6-46. doi:10.11 11/sipr. 12017
37. Espaillat A, Panna DK, Goede DL, Gurka MJ, Novak MA, Zaidi Z. An exploratory study on microaggressions in medical school: what are they and why should we care? Perspect Med Educ. 2019;8(3):143-151. doi:10.1007/s40037-019-0516-3

38. Osseo-Asare A, Balasuriya L, Huot SJ, et al. Minority resident physicians' views on the role of race/ethnicity in their training experiences in the workplace. JAMA Netw Open. 2018;1(5): e182723. doi:10.1001/jamanetworkopen.2018.2723

39. Yoshino K. The new equal protection. Harv Law Rev. 2011; 124:1-58.

40. Proud D, Kay AC. How perceptions of one's organization can affect perceptions of the self: membership in a stable organization can sustain individuals' sense of control. J Exp Soc Psychol. 2018;76:104-115. doi:10.1016/j.jesp.2018.01.004

41. Cox D, Lienesch R, Jones RP Beyond economics: fear of cultural displacement pushed the white working-class to Trump. PRRI/ The Atlantic Report. Available from: https://www.prri.org/ research/white-working-class-attitudes-economy-tradeimmigration-election-donald-trump/. Accessed July 15, 2018.

42. Putnam RD. Bowling Alone: The Collapse and Revival of American Community. New York: Simon \& Schuster; 2000.

43. Norton MI, Sommers SR. Whites see racism as a zero-sum game that they are now losing. Perspect Psychol Sci. 2011;6 (3):215-218. doi:10.1177/1745691611406922

44. Craig MA, Richeson JA. Information about the US racial demographic shift triggers concerns about anti-white discrimination among the prospective white "minority". PLoS One. 2017;12(9): e0185389. doi:10.1371/journal.pone.0185389

45. Wilkins CL, Kaiser CR. Racial progress as threat to the status hierarchy implications for perceptions of anti- white bias. Psychol Sci. 2014;25(2):439-446. doi:10.1177/0956797613508412

46. Craig MA, Richeson JA. On the precipice of a "majorityminority" America: perceived status threat from the racial demographic shift affects white Americans' political ideology. Psychol Sci. 2014;25:1189-1197. doi:10.1177/0956797614527113

47. Craig MA, Richeson JA. More diverse yet less tolerant? How the increasingly diverse racial landscape affects white Americans' racial attitudes. Pers Soc Psychol Bull. 2014;40:750-761. doi:10. $1177 / 0146167214524993$

48. Mutz DC. Status threat, not economic hardship, explain the 2016 election. PNAS. 2018;115(19):E4330-E4339. doi:10.1073/pnas. 1718155115

49. Pratto F, Sidanius J, Levin S. Social dominance theory and the dynamics of intergroup relations: taking stock and looking forward. Eur Rev Soc Psychol. 2006;17:271-320. doi:10.1080/ 10463280601055772

50. Nicol AA, Rounding K. Alienation and empathy as mediators of the relation between social dominance orientation, right-wing authoritarianism and expressions of racism and sexism. Pers Individ Dif. 2013;3:294-299. doi:10.1016/j.paid.2013.03.009

51. Tausch N, Hewstone M. Social dominance orientation attenuates stereotype change in the face of disconfirming information. Soc Psychol. 2010;41:169-176. doi:10.1027/1864-9335/a000 024

52. Lepièce B, Reynaert C, van Meerbeeck P, et al. Social dominance theory and medical specialty choice. Adv Health Sci Educ. 2016;21:79-92. doi:10.1007/s10459-015-9612-2

53. Eagly AH, Diekman AB. What is the problem? Prejudice as an attitude-in-context. Nat Prejudice. 2005;50:19-35.

54. Bobo LD, Fox C. Race, racism, and discrimination: bridging problems, methods, and theory in social psychological research. Soc Psychol Q. 2003;66:319-332. doi:10.2307/1519832

55. Brewer M, Miller N. Beyond the contact hypothesis: theoretical perspectives on desegregation. In: Miller N, Brewer M, editors. Group in Contact: The psychology of Desegregation. Orlando, FL: Academic Press; 1984:281-302. 
56. Kotchoubey B. Human consciousness: where is it from and what is it for. Front Psychol. 2018;9:567. doi:10.3389/fpsyg.2018.00567

57. Selmi M. The Paradox of Implicit Bias and a Plea for a New Narrative. Ariz St L J. 2018;50:193.

58. Gawronski B, Hofmann W, Wilbur CJ. Are "implicit" attitudes unconscious? Conscious Cogn. 2006;15:485-499. doi:10.1016/j. concog.2005.11.007

59. Chaet DH. AMA code of medical ethics' opinions related to discrimination and disparities in health care. AMA J Ethics. 2016;18(11):1095-1097. doi:10.1001/journalofethics.2016.18.11. coet $1-1611$

60. Riess H. The science of empathy. J Patient Exp. 2017;4(2):74-77. doi: $10.1177 / 2374373517699267$

61. Han S. Neurocognitive basis of racial ingroup bias in empathy. Trend Cog Sci. 2018;22(5):400-421. doi:10.1016/j.tics.2018.02.013

62. Yuguero O, Esquerda M, Viñas J, Soler-Gonzalez J, Pifarré J. Ethics and empathy: the relationship between moral reasoning, ethical sensitivity and empathy in medical students. Reumatol Clin. 2019;219(2):73-78. doi:10.1016/j.rceng.2018.09.009

63. Hardeman RR, Przedworski JM, Burke S, et al. Association between perceived medical school diversity climate and change in depressive symptoms in medical students: a report from the medical student CHANGE study. J Natl Med Assoc. 2016;108 (4):225-235. doi:10.1016/j.jnma.2016.08.005

64. Cuesta-Briand B, Auret K, Johnson P, Playford D. 'A world of difference': a qualitative study of medical students' views on professionalism and the 'good doctor'. BMC Med Educ. 2014;14:77. doi:10.1186/1472-6920-14-77

65. Brockbank S, David TJ, Patel L. Unprofessional behavior in medical students: A questionnaire-based pilot study comparing perceptions of the public with medical students and doctors. Med Teach. 2011;33:e501-e508. doi:10.3109/0142159X.2011.599450

66. van Ryn M, Hardeman R, Phelan SM, et al. Medical school experiences associated with change in implicit racial bias among 3547 students: a medical student CHANGES study report. J Gen Intern Med. 2015;30(12):1748-1756. doi:10.1007/s11606-0153447-7

67. van Ryn M, Phelan SM. Response to Dr. Westall. J Gen Intern Med. 2016;31:715. doi:10.1007/s11606-016-3683-52

68. Dehon E, Weiss N, Jones J, Faulconer W, Hinton E, Sterling S. A systematic review of the impact of physician implicit racial bias on clinical decision making. Acad Emerg Med. 2017;24 (8):895-904. doi:10.1111/acem.13214

69. 60 Minutes/Vanity Fair. Do Americans really believe that all men are created equal? September 2015. Available from: https://www. vanityfair.com/news/201507vanity-fair-60-minutes-pollinequality. Accessed November 14, 2017.

70. Bean MG, Focella ES, Covarrubias R, et al. Documenting nurses and medical students' stereotypes about hispanic and native American patients. J Health Dispar Res Pract. 2014;7(3):14-22.

71. van Ryn M, Burke J. The effect of patient race and socioeconomic status on physicians' perceptions of patients. Soc Sci Med. 2000;50(6):813-828. doi:10.1016/S0277-9536(99)00338-X

72. Hunter M. Colorism in the classroom: how skin tone African-American and Latina/o students. Theory Pract. 2016;55 (1):54-61. doi:10.1080/00405841.2016.1119019

73. Hall WJ, Chapman MV, Lee KM, et al. Implicit racial/ethnic bias among health care professionals and its influence on health care outcomes: a systematic review. Am J Public Health. 2015;105 (12):e60-e76. doi:10.2105/AJPH.2015.302903

74. Fitzgerald C. Implicit bias in healthcare professionals: a systematic review. BMC Med Ethics. 2017;18:19. doi:10.1186/ s12910-017-0179-8

75. Hurd K, Plaut VC. Diversity-benefits ideology undermine inclusion? Diversity entitlement: does. NW U L Rev. 2017;112 (6):1607-1634.
76. Mana I, Belton T, Ginzbergh S, Singh A, Johnson T. A decade of studying implicit racial/ethnic bias in healthcare providers using the implicit association test. Soc Sci Med. 2018;199:219-229. doi:10.1016/j.socscimed.2017.05.009

77. Ogle J, Bushnell JA, Caputi P. Empathy is related to clinical competence in medical care. Med Educ. 2013;47(8):824-831. doi:10.1111/medu. 12232

78. Hojat M, Gonnella JS, Mangione S, et al. Empathy in medical students as related to academic performance, clinical competence and gender. Med Educ. 2002;36(6):522-527. doi:10.1046/j.13652923.2002.01234.x

79. Teherani A, Hauer KE, Fernandez A, King TE Jr., Lucey C. How small differences and assess clinical performance amplify to large differences in grades and awards: a cascade with serious consequences for students underrepresented in medicine. Acad Med. 2018;93(9):1286-1292. doi:10.1097/ACM.0000000000002323

80. Stone J, Moskowitz GB. Non-conscious bias in medical decision making: what can be done to reduce it? Med Educ. 2011;45:768-776. doi:10.1111/j.1365-2923.2011.04026.x

81. Green AR, Carney DR, Pallin DJ, et al. Implicit bias among physicians and its prediction of thrombolysis decisions for black and white patients. J Gen Intern Med. 2007;22(9):1231-1238. doi: 10.1007/s11606-007-0258-5

82. Stratton TD, Saunders JA, Elam CL. Changes in medical students' emotional intelligence: an exploratory study. Teach Learn Med. 2008;20:279-284. doi:10.1080/10401330802199625

83. Sasahara K, Chen W, Peng H, Ciampaglia GL, Flammini A, Menczer $\mathrm{F}$ On the inevitability of online echo chambers. Available from: https://arxiv.org/abs/1905.03919v2. Accessed May 27, 2020

84. Jamieson KH, Cappella JN. Echo Chamber: Rush Limbaugh and the Conservative Media Establishment. Oxford University Press; 2008.

85. Brugnoli E, Cinelli M, Quattrociocchi W, et al. Recursive patterns in online echo chambers. Sci Rep. 2019;9:20118. doi:10.1038/ s41598-019-56191-7

86. Hogg MA, Rinella MJ. Social identities and shared realities. Cur Opin Psychol. 2018;23:6-10. doi:10.1016/j.copsyc.2017.10.003

87. Iyengar S, Sood G, Lelkes Y. Affect, not ideology: a social identity perspective on polarization. Public Opin Q. 2012;76 (3):405-431. doi:10.1093/poq/nfs038

88. Quattrociocchi W, Scala A, Sunstein CR. Echo Chambers on Facebook. SSRN Electron J. 2016. doi:10.2139/ssrn.2795110

89. Rychwalska A, Roszczyńska-Kurasińska M Polarization on social media: when group dynamics leads to societal divides. Proceedings of the 51st Hawaii International Conference on System Sciences; 2018. Available from: https://scholarspace. manoa.hawaii.edu/bitstream/10125/50150/paper0263.pdf. Accessed May 27, 2020.

90. Nai A. The trump paradox: how cues from a disliked source foster resistance to persuasion. Politics Gov. 2020;8(1):122-132. doi:10. 17645/pag.v8i1.2428

91. Valutis SA. The relationship between tolerance of ambiguity and stereotyping: implications for BSW education. J Teach Soc Work. 2015;35(5):513-528. doi:10.1080/08841233.2015.1088927

92. Wayne S, Dellmore D, Serna L, Jerabek R, Timm C, Kalishman S. The association between intolerance of ambiguity and decline in medical students' attitudes toward the underserved. Acad Med. 2011;86(7):877-882. doi:10.1097/ACM.0b013e31821dac01

93. Luzsa R, Mayr S. Links between users' online social network homogeneity, ambiguity tolerance, and estimated public support for own opinions. Cyberpsychol Behav Soc Netw. 2019;22 (5):325-329. doi:10.1089/cyber.2018.0550

94. Ross HJ. Everyday Bias: Identifying and Navigating Unconscious Judgments in Our Daily Lives. Lanham, MD: Rowman \& Littlefield; 2014. 
95. Johnson I, Donovan D, Parboosingh J. Steps to improve the teaching of public health to undergraduate medical students in Canada. Acad Med. 2008;83:414418. doi:10.1097/ACM.0b013e $318166 \mathrm{a} 8 \mathrm{e} 4$

96. Zollo F. Dealing with digital misinformation: a polarized context of narratives and tribes. EFSA J. 2019;17(S1):e170720. doi:10. 2903/j.efsa.2019.e170720

97. Martimianakis MA, Michalec B, Lam J, Cartmill C, Taylor JS, Hafferty FW. Humanism, the hidden curriculum, and educational reform: a scoping review and thematic analysis. Acad Med. 2015;90(11):S5-S13. doi:10.1097/ACM.0000000000000894

98. Balmer DF, Hall E, Fink M, Richards BF. How do medical students navigate the interplay of explicit curricula, implicit curricula, and extracurricula to learn curricular objectives? Acad Med. 2013;88(8):1135-1141. doi:10.1097/ACM.0b013e31829a $6 \mathrm{c} 39$

99. Mackie D, Devos T, Smith E. Intergroup emotions: insights from a theoretically integrative approach. J Pers Soc Psychol. 2000;79:602-616. doi:10.1037/0022-3514.79.4.602

100. Phelan SM, Burke SE, Hardeman RR, et al. Medical school factors associated with changes in implicit and explicit bias against gay and lesbian people among 3492 graduating medical students. J Gen Int Med. 2017;32(11):1193-1201. doi:10.1007/s1 1606-017-4127-6

101. Brazeau CM, Schroeder R, Rovi S, Boyd L. Relationship between medical student service and empathy. Acad Med. 2011;86(10 Suppl):S42-5. doi:10.1097/ACM.0b013e31822a6ae0

102. Schripsema NR, van Trigt AM, van der Wal MA, CohenSchotanus J. How different medical school selection processes call upon different personality characteristics. PLoS One. 2016;11 (3):e0150645. doi:10.1371/journal.pone.0150645

103. de Visser M, Fluit C, Cohen-Schotanus J, Laan R. The effects of a non-cognitive versus cognitive admission procedure within cohorts in one medical school. Adv Heal Sci Educ. 2018;23: 187-200. doi:10.1007/s10459-017-9782-1

104. Wilson I, Griffin B, Lampe L, et al. Variation in personality traits of medical students between schools of medicine. Med Teach. 2013;35(11):944-948. doi:10.3109/0142159X.2013.827331

105. Haight SJ, Chibnall JT, Schindler DL, Slavin SJ. Associations of medical student personality and health/wellness characteristics with their medical school performance across the curriculum. Acad Med. 2012;87(4):476-485. doi:10.1097/ACM.0b013e31824 $8 \mathrm{e} 9 \mathrm{~d} 0$

106. Quinlivan JA, Lam LT, Wan SH, Petersen RW. Selecting medical students for academic and attitudinal outcomes in a Catholic medical school. Med J Aust. 2010;193(6):347-350. doi:10.5694/ j.1326-5377.2010.tb03947.x

107. Tajeu GS, Cherrington AL, Andreae L, Prince C, Holt CL, Halanych JH. "We'll Get to You When We Get to You": exploring potential contributions of health care staff behaviors to patient perceptions of discrimination and satisfaction. Am J Public Health. 2015;105(10):2076-2082. doi:10.2105/AJPH.2015.302 721

108. Ansell DA, McDonald EK. Bias, black lives, and academic medicine. N Engl J Med. 2015;372(12):1087-1089. doi:10.1056/ NEJMp1500832

109. Babyar J. Equitable health: let's stick together as we address global discrimination, prejudice and stigma. Arch Public Health. 2018;76(1):44. doi:10.1186/s13690-018-0291-3

110. Murphy SL, Xu J, Kockanek KD Deaths: final data for 2010. National Vital Statistics Reports; 2013:61.

111. Colen CG, Ramey DM, Cooksey EC, Williams DR. Racial disparities in health among nonpoor African Americans and Hispanics: the role of acute and chronic discrimination. Soc Sci Med. 2018;199:167-180. doi:10.1016/j.socscimed.2017.04.051
112. Golash-Boza T, Darity W. Latino racial choices: the effects of skin colour and discrimination on Latinos' and Latinas' racial self-identifications. Ethn Racial Stud. 2008;31(5):899-934. doi:10.1080/01419870701568858

113. Brown v. Bd. of Educ., 347 U.S. 483 at 493

114. Regents of Univ. of Cal. v. Bakke, 438 U.S. 265 at 321-24.

115. Grutter v. Bollinger, 539 U.S. 306 at 331-32

116. Fisher v. Univ. of Tex. at Austin (Fisher I), 570 U.S. 297

117. Feingold JP Hidden in plain sight: a more compelling case for diversity. Utah Law Review: Vol. 2019: No. 1, Article 2. Available from: https://dc.law.utah.edu/ulr/vol2019/iss1/2. Accessed May 17, 2019

118. Claridge H, Stone K, Ussher M. The ethnicity attainment gap among medical and biomedical science students: a qualitative study. BMC Med Educ. 2018;18:325. doi:10.1186/s12909-0181426-5

119. Keyishian et al. v.Board of Regents of the University of the State of New York et al. 385 U.S. 589 at 603; 1967

120. Grutter v. Bollinger. 539 U.S. 306 at 333, 334; 2003.

121. Bardes CL. Teaching, digression, and implicit curriculum. Teach Learn Med. 2004;16:212-214. doi:10.1207/s15328015tlm16 $02 \_15$

122. Tavakol S, Dennick R, Tavakol M. Medical students' understanding of empathy: A phenomenological study. Med Educ. 2012;46:306-316. doi:10.1111/j.1365-2923.2011.04152.x

123. Eikeland HL, Ornes K, Finset A, Pedersen R. The physician's role and empathy - A qualitative study of third year medical students. BMC Med Educ. 2014;14:165-173. doi:10.1186/14726920-14-165

124. Ratanawongsa N, Teherani A, Hauer KE. Third-year medical students' experiences with dying patients during the internal medicine clerkship: A qualitative study of the informal curriculum. Acad Med. 2005;80:641-647. doi:10.1097/00001888-20050 7000-00006

125. Lutz G, Scheffer C, Edelhaeuser F, Tauschel D, Neumann M. A reflective practice intervention for professional development, reduced stress and improved patient care-A qualitative developmental evaluation. Patient Educ Couns. 2013;92:337-345. doi:10. 1016/j.pec.2013.03.020

126. Cruess SR, Cruess RL, Steinert Y. Role modelling-Making the most of a powerful teaching strategy. BMJ. 2008;336:718-721. doi:10.1136/bmj.39503.757847.BE

127. Marcum JA. The role of empathy and wisdom in medical practice and pedagogy: confronting the hidden curriculum. J Biomed Educ. 2013;1-8.

128. Kozéki B, Berghammer R. The role of empathy in the motivational structure of school children. Pers Individ Dif. 1992;13:191-203. doi:10.1016/0191-8869(92)90042-N

129. Association American Medical Colleges. 2017 Matriculating Student Questionnaire. All Schools Summary. Association American Medical Colleges; July 7, 2018.

130. Jargowsky PA Concentration of poverty in the new millennium: changes in the prevalence, composition, and location of high-poverty neighborhoods. The Century Foundation and Rutgers Center for Urban Research and Education; 2013. Available from: http://www.tcf.org/assets/downloads/ Concentration_of_Poverty_in_the_New_Millennium.pdf. Accessed May 27, 2020

131. Fry R, Taylor $P$ The rise of residential segregation by income. Pew Research Center; August 1, 2012. Available from: www. pewsocialtrends.org/2012/08/01/the-rise-of-residentialsegregation-by-income/. Accessed August 6, 2018.

132. Morrison E, Grbic D. Dimensions of diversity and perceptions of having learned from individuals from different backgrounds: the particular importance of racial diversity. Acad Med. 2015;90:937-945. doi:10.1097/ACM.0000000000000675 
133. Williams DR, Collins C. Racial residential segregation: A fundamental cause of racial disparities in health. Public Health Rep. 2001;116:404-416. doi:10.1016/S0033-3549(04) 50068-7

134. Public Religion Research Institute. Race and Americans' social networks. Public Religion Research Institute; 2013. Available from: http://publicreligion.org/research/2014/08/analysis-socialnetwork/\#.VTmjK61Vikp. Accessed May 27, 2020.

135. Gurin P Expert Report of Patricia Gurin at app. E, Gratz v. Bollinger, 135 F. Supp. 2d 790 (E.D. Mich. 2ooi) (No. 97-75321), Grutter v. Bollinger, 137 F. Supp. 2d 874 (E.D. Mich. 2001) (No. 97-75928).

136. Gurin G, Matlock J Michigan Student Study: opinions, Expectations, and Experiences of Undergraduate Students, 1990-1994. Ann Arbor, MI: Inter-university Consortium for Political and Social Research [distributor]; December 15, 2005. doi: 10.3886/ICPSR04027.v1.

137. Rockenbach AN, Mayhew MJ, Correia-Harker BP, et al. Navigating Pluralism. Interfaith Diversity Experiences and Attitudes Longitudinal Survey 2017. 2017; Chicago Illinois: Interfaith Youth Core

138. Cao Y, Contreras-Huerta LS, McFadyen J, Cunnington R. Racial bias in neural response to others' pain is reduced with other-race contact. Cortex. 2015;70:68-78. doi:10.1016/J.Cortex.2015.02. 010
139. Meadows A, Higgs S, Burke SE, Dovidio JF, van Ryn M, Phelan SM. Social dominance orientation, dispositional empathy, and need for cognitive closure moderate the impact of empathyskills training, but not patient contact, on medical students' negative attitudes toward higher-weight patients. Front Psychol. 2017;8:504. doi:10.3389/fpsyg.2017.00504

140. Burke SE, Dovidio JF, Przedworski JM, et al. Do contact and empathy mitigate bias against gay and lesbian people among heterosexual first-year medical students? A report from the medical student CHANGE study. Acad Med. 2015;90(5):645-651. doi:10.1097/ACM.0000000000000661

141. Sidanius J, Pratto F. Social Dominance: An Intergroup Theory of Social Hierarchy and Oppression. Cambridge University Press; 1999:46-47.

142. Wieland ML, Beckman TJ, Cha SS, Beebe TJ, McDonald FS; Underserved Care Curriculum Collaborative. Resident physicians' knowledge of underserved patients: a multi-institutional survey. Mayo Clin Proc. 2010;85(8):728-733. doi:10.4065/mcp. 2009.0703

143. Marshall JK, Cooper LA, Green AR, et al. Residents' attitude, knowledge, and perceived preparedness toward caring for patients from diverse sociocultural backgrounds. Health Equity. 2017;1:43-49. doi:10.1089/heq.2016.0010

144. Fulbright W. The Price of Empire. New York, NY: Pantheon Press; 1989:xi.
Advances in Medical Education and Practice

\section{Publish your work in this journal}

Advances in Medical Education and Practice is an international, peerreviewed, open access journal that aims to present and publish research on Medical Education covering medical, dental, nursing and allied health care professional education. The journal covers undergraduate education, postgraduate training and continuing medical education

\section{Dovepress}

including emerging trends and innovative models linking education, research, and health care services. The manuscript management system is completely online and includes a very quick and fair peer-review system. Visit http://www.dovepress.com/testimonials.php to read real quotes from published authors. 